Impacto del pago de las regalías en el valor en aduana de las mercancías importadas

Julio Guadalupe Báscones

En el presente artículo, el autor propone un método de valoración aduanera para la determinación de la base imponible de los tributos de importación a las mercancías importadas.

Socio de Rodrigo, Elías \& Medrano abogados. Miembro de la Academia Internacional de Derecho Aduanero. 


\section{Impacto del pago de regalías en el valor en aduana de las mercancías importadas}

\section{Introducción.}

El cruce de mercancías por las fronteras de los países genera fenómenos jurídicos de necesario estudio y regulación. Tanto la importación como la exportación de mercancías siempre han requerido y requerirán el control de las autoridades competentes en relación con ámbitos tales como salud pública, seguridad nacional, tributario, entre otros. La rama del derecho que estudia estos fenómenos jurídicos es el Derecho Aduanero, el mismo que en las últimas décadas ha venido evolucionando importantemente y de manera constante hasta gozar, hoy por hoy, de una autonomía indiscutida conforme a autorizada doctrina. Reconocidos autores como Ricardo Basaldúa, Andrés Rhode y Juan Patricio Cotter coinciden en señalar que la materia aduanera cuenta con un contenido que le es propio, manifestándose su autonomía en los ámbitos: i) científico [control sobre el tráfico internacional de mercancías como finalidad específica; instituciones propias (territorio aduanero, mercadería, importación, exportación, etc. ); organización particular conforme a sus fines (ámbitos administrativo, penal, tributario, etc.)]; ii) didáctico (doctrina especializada, eventos académicos especializados); y iii) legislativo (normativa propia).El aspecto tributario del Derecho Aduanero comprende todas aquellas regulaciones relacionadas con el nacimiento de la obligación tributario-aduanera, la misma que en nuestro país se genera en los denominados regímenes de ingreso, dentro de los cuales se encuentra la importación definitiva. En función a ello, resultará indispensable determinar con exactitud los aspectos constitutivos de la hipótesis de incidencia tributario-aduanera conforme a los parámetros establecidos tanto en la Ley General de Aduanas como en la normativa especial que regula el tratamiento legal de los denominados tributos de importación (Impuesto General a las Ventas (IGV), por ejemplo). ${ }^{1}$

Uno de los aspectos de la referida hipótesis de incidencia tributario-aduanera es el "cuantitativo", el mismo que está relacionado directamente con la determinación del "quantum" de los tributos de importación; es decir, su connotación mensurable en términos económicos. A dichos efectos, dos puntos resultan relevantes: i) la determinación de la base imponible; y ii) la determinación de la alícuota (tasa del impuesto).

1 Para mayores precisiones sobre los alcances y connotaciones de la hipótesis de incidencia tributario-aduanera, recomiendo la lectura de un artículo elaborado en coautoría con Charles Castle denominado "Valoración Aduanera del Software ¿Y el Principio de Reserva de Ley?". En: Revista Derecho y Sociedad No. 27, pp. $107-113$. 
El respecto Germán Pardo señala, al referirse a la definición de los elementos esenciales del hecho imponible de la hipótesis de incidencia tributaria-aduanera, que "en lo que se refiere a la base imponible y al tipo o tarifa, es decir, los elementos cuantificadores del derecho aduanero (...) la base imponible es objeto del Código del Valor del GATT (OMC)" mientras que el "tipo o tarifa" comprende "la cifra, coeficiente o porcentaje que se aplica sobre la base imponible para obtener el gravamen". Al respecto, y mayor abundamiento, el profesor Pardo señala también que tanto el "parámetro o base gravable y el tipo o tarifa son elementos de cuantificación de la obligación tributaria principal por lo que están precedidos en su regulación por el principio de reserva de ley".²

En el presente artículo nos ocuparemos de desarrollar el primero de los dos elementos del aspecto cuantitativo de la hipótesis de incidencia tributario-aduanera (determinación de la base imponible para el cálculo de los tributos de importación), el mismo que se encuentra regulado por la normativa sobre Valoración Aduanera aprobada por la Organización Mundial de Comercio (OMC).

Sobre la materia, Santiago Ibáñez señala que la Valoración Aduanera constituye "una materia compleja y escasamente tratada a pesar de que, como veremos, estamos ante una cuestión respecto de la cual se suscitan un buen número de dudas en la práctica cuya resolución, de otro lado, nos lleva en último término a plantear interrogantes de gran calado para la cabal compresión del ordenamiento tributario actual ${ }^{\prime 3}$.

Partiendo de esta afirmación, corresponde solo añadir que la Valoración Aduanera constituye una metodología especializada que sigue su propia lógica, estructura y reglas; y que no necesariamente debe o tiene que encontrarse en consonancia con la normativa tributaria general ni con la interpretación que se pueda tener de esta última. De otro lado, y la luz de nuestra práctica profesional, podríamos afirmar que esta materia podría revestir, en algunos casos, niveles de complejidad muy altos. El tema sobre el que versa el presente artículo es precisamente uno de ellos ${ }^{4}$.

\section{Acuerdo del valor en aduana de la Organización Mundial del Comercio (OMC).}

2 Pardo Carrero, Germán, Tributación Aduanera, Legis Editores S.A., Bogotá, 2009, pp.125, 408 y 466.

3 Ibañez Marsilla, Santiago, El valor en aduana. Análisis a la luz de su aplicación internacional, Editorial Taric S.A., Primera Edición, 2010, pp. 23

$4 \quad$ A los efectos de advertir la complejidad que podría revestir el tema puntual de los ajustes por concepto de pago de regalías en materia aduanera recomendamos la lectura de un artículo del profesor Daniel Zolezzi denominado "Las marcas, las patentes y el valor en aduana (en instrumentos de la Organización Mundial de Aduanas y en la jurisprudencia)" publicado el 18 de abril de 2013 en el Diario de Doctrina y Jurisprudencia "El Derecho". 
El Acuerdo relativo a la aplicación del artículo VII del Acuerdo General sobre Aranceles y Comercio de la Organización Mundial de Comercio - OMC (en adelante "el Acuerdo") ${ }^{5}$ busca, de manera primordial, el establecimiento de un sistema de valoración en aduana equitativo y no distorsionante, que excluya la utilización de valores arbitrarios o ficticios ("de laboratorio").

En función a esta directriz, y conforme al Acuerdo, la base de la valoración aduanera debe ser "en la mayor medida posible" el valor de transacción de las mercancías importadas ${ }^{6}$; esto es, el valor declarado por el importador sobre la base de las características propias de la operación comercial (venta) que sustenta su importación. En función a ello, cualquier incremento (ajuste) del precio realmente pagado o por pagar por el comprador (importador) al vendedor (proveedor extranjero) podrá ser efectuado en la medida que se cumplan las condiciones y requisitos que, para tal fin, han sido establecidos expresamente y de modo objetivo en el Acuerdo ${ }^{7}$.

Todo ello, conforme lo señala el Acuerdo, con la finalidad de que la valoración aduanera de las mercancías importadas constituya una metodología de aplicación uniforme y que genere certidumbre.

En cuanto al tema de la aplicación uniforme de las disposiciones del Acuerdo, es de mencionar que, conforme este mismo dispone, se ha establecido la creación del denominado Comité Técnico de Valoración en Aduana ${ }^{8}$, entidad que emite pronunciamientos a modo de opiniones de nivel técnico que tienden a generar uniformidad en la interpretación y aplicación del Acuerdo entre las aduanas de los países miembros de la OMC.

$5 \quad$ El Acuerdo fue incorporado a la legislación peruana mediante Resolución Legislativa 26407 vigente desde el 1 de enero de 2000.

$6 \quad$ Las reglas sobre Valoración Aduanera de la OMC establecen seis (06) métodos para la determinación del valor en Aduana de las mercancías importadas. El primero de ellos es el denominado "Método del Valor de Transacción de las Mercancías Importadas" y constituye el principal método de valoración aduanera y, además, el más utilizado. El presente artículo está relacionado con los ajustes al precio declarado por el importador bajo los alcances de este método. Para mayores referencias sobre los métodos establecidos por el Acuerdo recomendamos la lectura del artículo de Lourdes Aguilar denominado "Nuevas reglas de valoración aduanera para la importación de mercancías". En: Revista Themis No. 41, pp. 205-210.

7 El Acuerdo fue incorporado a la legislación peruana mediante Resolución Legislativa 26407 vigente desde el 1 de enero de 2000.

8 Comité instaurado, conforme al Acuerdo, bajo los auspicios del Consejo de Cooperación Aduanera, que tiene por finalidad, entre otras, la de examinar los problemas técnicos concretos que surjan de la administración continua de los sistemas de valoración en aduana de los países miembros de la OMC, así como emitir opinión acerca de las soluciones pertinentes sobre la base de los hechos que le son expuestos. 
Aunque estos pronunciamientos no constituyen una norma internacional, sino simples recomendaciones; es de advertir que en el caso peruano todos los instrumentos expedidos por el Comité Técnico han sido incorporados a la legislación nacional ${ }^{9}$, convirtiendo en obligatorias opiniones de dicho Comité que analizan situaciones puntuales con determinadas características que no siempre tienen que ser exactamente iguales a las que se presentan en los casos concretos que requieren ser analizados.

Este asunto cobra aún más importancia si tenemos en consideración que la normativa sobre valoración aduanera es de naturaleza tributaria ya que sirve, como lo hemos mencionado anteriormente, para determinar la base imponible de los tributos de importación (aspecto cuantitativo de la hipótesis de incidencia, en este caso, tributarioaduanera).

En la práctica, la incorporación de los instrumentos del Comité a la legislación nacional genera una complicación particular pues la Autoridad Aduanera podría pretender forzar la aplicación de un determinado instrumento del Comité bajo la consideración que existe la "obligación" de aplicarlo sin realizar un análisis de legalidad adecuado y exhaustivo (como se requiere muy en especial en la materia tributaria) para verificar que el caso concreto objeto de análisis se encuentra perfectamente comprendido dentro del hecho imponible establecido por la norma, a fin de que la "aplicación directa" del instrumento del Comité de que se trate resulte legítima.

En relación con estas complicaciones, Juan David Barbosa señala que "(...) en la medida que el Comité Técnico de Valoración no tiene la potestad de alterar o ampliar la redacción del Acuerdo, sus decisiones sólo tienen carácter interpretativo (...) en este sentido, pretender normativizar estos instrumentos de interpretación puede resultar contrario a las disposiciones del Acuerdo mismo, con el problema adicional que en algunos casos la discusión para aplicar o no la orientación puede versar sobre si los elementos de hecho son o no idénticos, y esto difícilmente puede ser normativizado" ${ }^{10}$.

Lo cierto es que en el Perú, como ya se dijo, los instrumentos expedidos por el Comité son norma tributaria y, por tanto, de obligatoria aplicación, siempre que la situación descrita dentro de dichos instrumentos calce de modo exacto con los hechos tenidos en consideración por el Comité al momento de emitir su opinión. Esta situación, de por si

9 Mediante el Decreto Supremo 186-99-EF (norma que aprobó el Reglamento de Valoración en Aduana de la OMC) fueron incorporados a la legislación peruana las Decisiones del Comité de Valoración Aduanera y los Instrumentos expedidos por el Comité Técnico de Valoración en Aduanas, entre ellos, las Opiniones Consultivas, Comentarios, Notas Explicativas, Estudio de Casos y Estudios.

10 Barbosa Mariño, Juan David, "La Valoración Aduanera en las Mercancías. Efectos del nuevo Reglamento Comunitario Andino en materia de Valoración Aduanera". En: Revista "Análisis Tributario" Vol. XXVII No. 319, agosto 2014, pp. 35. 
compleja (ya que los instrumentos del Comité fueron, en principio, concebidos para ser orientativos y no vinculantes), origina que la aplicación de dichos instrumentos resulte un tema del todo sensible que requiere de un análisis serio y técnico que proscriba "fórmulas" que propugnen echar mano de una pretendida "racionalidad" que no haría más que extender indebida e ilegalmente los supuestos de hecho de la norma tributaria a situaciones no comprendidas en ella.

Tenemos que recordar que, conforme a lo dispuesto en el Preámbulo del Acuerdo, este busca el establecimiento de un sistema de valoración en aduana equitativo y no distorsionante que excluya la utilización de valores arbitrarios o ficticios ("de laboratorio") generando uniformidad y certidumbre. En relación con ello, suscribimos lo indicado por el profesor Daniel Zolezzi cuando afirma que "no se quiere que el valor en aduana quede librado al criterio azaroso del funcionario de turno. Cuando las normas de valor no son neutras y precisas, el umbral que separa lo subjetivo de lo arbitrario se hace estrecho. Por eso, el Acuerdo aspira a brindar "uniformidad y certidumbre" - principios de inestimable valor para la fluidez del comercio - a través de "un sistema equitativo, neutro y uniforme", excluyendo "... la utilización de valores arbitrarios o ficticios" ${ }^{11}$

\section{La mercancía importada como objeto de la valoración aduanera.}

Teniendo en consideración lo antes señalado, debemos indicar que el objeto de la valoración aduanera (lo que se valora) son las mercancías. Es decir, mediante esta normativa se busca determinar el valor en aduana de la "mercancía importada".

Al respecto, es de mencionar que, tal como afirma el profesor Ricardo Basaldúa, "para el Derecho Aduanero la voz "mercadería" designa a un elemento esencial, a un presupuesto básico del mismo, ya que constituye el objeto de tráfico internacional cuyo ingreso 0 egreso a través de fronteras aduaneras da lugar a los fenómenos de la "importación" y "exportación" que deben ser controlados por las aduanas". ${ }^{12} \mathrm{Y}$ es que, conforme a la normativa aduanera, constituyen "mercancías" aquellos bienes que cuenten con la aptitud $y$, por ende, puedan ser susceptibles de ser sometidos a los controles, reglamentaciones y procedimientos que tales regímenes, operaciones y destinos imponen.

En lo que respecta puntualmente al régimen de importación definitiva, este está relacionado con el ingreso legal de mercancías provenientes del exterior para ser destinadas al consumo ${ }^{13}$. Para que las mercancías puedan "provenir del exterior"

11 Zolezzi, Daniel, Valor en Aduana (Código Universal de la OMC), Segunda Edición, Editorial La Ley S.A.E, Buenos Aires, 2008, pp.17.

12 Basaldúa, Ricardo Xavier, Derecho Aduanero. Parte General, Abeledo Perrot, Buenos Aires, 1992, pp. $53-54$.

13 El artículo 52 de la Ley General de Aduanas estipula que la importación definitiva es el "régimen que permite el ingreso legal de mercancías provenientes del exterior para ser destinadas al consumo". 
requieren previamente haber sido embarcadas para su exportación a Perú, haber sido objeto de transporte internacional (lo cual implica también las actividades asociadas tanto de carga / estiba como de desestiba / descarga) y haber sido sometidas a los controles aduaneros que el régimen de importación definitiva impone (lo cual incluye contar con la aptitud de poder ser objeto de revisión física de ser ello requerido conforme al canal de control (rojo) pertinente). Otra característica importante es que la mercancía pueda ser clasificada en una Subpartida Arancelaria con la finalidad de obtener la tasa arancelaria correspondiente y determinar si su ingreso al país pudiese resultar prohibido o restringido. Como se aprecia, la característica esencial de las mercancías que pueden ser objeto de importación y, por ende, de valoración aduanera, es su corporeidad; es decir, su condición de bienes físicos ${ }^{14}$.

Ahora bien, si lo que se valora en aduana son las mercancías importadas (bienes físicos) ¿Qué connotación particular podrían tener los bienes intangibles a dichos efectos? ¿Resultará importante el determinar aduaneramente el valor de un bien intangible si este no constituye el objeto de la valoración aduanera?

Sobre el particular, es de indicar que el valor en aduana de las mercancías importadas puede ser pasible de incrementos o ajustes conforme dispone el propio Acuerdo. Uno de estos ajustes es el relativo a los cánones o derechos de licencia (en adelante "regalías"), al cual nos referiremos seguidamente. Empero, reiteramos que cualquier incremento o ajuste al valor en aduana declarado por el importador sólo resultará válido si se cumplen de manera escrupulosa todos y cada uno de los requisitos establecidos por el Acuerdo para tal fin.

\section{Ajustes al valor en aduana por concepto de pago de regalías.}

El literal c) del numeral 1 del artículo 8 del Acuerdo del Valor de la OMC establece que para determinar el valor en aduana de conformidad con lo dispuesto en el artículo 1 , se añadirán al precio realmente pagado o por pagar por las mercancías importadas, entre otros, los cánones y derechos de licencia (regalías) relacionados con las mercancías objeto de valoración que el comprador tenga que pagar directa o indirectamente como condición de venta de dichas mercancías, en la medida en que los mencionados cánones y derechos no estén incluidos en el precio realmente pagado o por pagar.

14 A excepción de, por ejemplo, la energía eléctrica (que cuenta con una subpartida propia), como regla general podemos afirmar que las mercancías que se encuentran comprendidas en el Arancel de Aduanas presentan una naturaleza corpórea, es decir, constituyen bienes físicos. Para mayor referencia sobre el particular se recomienda la lectura de un artículo de mi autoría denominado "Consideraciones aduaneras en relación al término "mercancía". En: Revista IUS ET VERITAS No. 35, pp. 23 - 33. 
La norma en referencia establece las pautas y sustento legal para la procedencia de los ajustes al precio realmente pagado o por pagar por las mercancías importadas ${ }^{15}$ por concepto de pago de regalías. En función a ello, y para que dicho ajuste cuente con asidero legal, se deberán cumplir todos y cada uno de los requisitos previstos por la norma. De ello se desprende que la ausencia de alguno o algunos de estos requisitos determine que este ajuste no pueda ser aplicado.

\subsection{Requisitos para la procedencia del ajuste relativo al pago de cánones y derechos de licencia}

A continuación procederemos a analizar cada uno de los requisitos establecidos por la norma.

(i) El pago de regalías deberá estar relacionado con las mercancías objeto de valoración.

Conforme dispone el Acuerdo, tiene que existir relación entre el pago efectuado por concepto de regalías y las mercancías que ingresaron al país sometidas al régimen de importación definitiva y que, por ende, fueron objeto de valoración aduanera. Así, el pago de la regalía deberá efectuarse como contraprestación por el derecho de uso y/o explotación de un intangible impuesto o gravado sobre la mercancía importada (marca), utilizado para la fabricación de la mercancía importada (patente) o relacionado con la creación intelectual de la mercancía importada (derechos de autor).

Al respecto, es de señalar que conforme al Diccionario de la Real Academia de la Lengua Española la palabra "relación" significa "conexión o correspondencia de una cosa con otra"; "conexión" significa "enlace, atadura, trabazón, concatenación de una cosa con

15 Conforme a lo señalado en la Nota Interpretativa al artículo 1 del Acuerdo "el precio realmente pagado o por pagar es el pago total que por las mercancías importadas haya hecho o vaya a hacer el comprador al vendedor o en beneficio de este. Dicho pago no tiene que tomar necesariamente la forma de una transferencia de dinero. El pago puede efectuarse por medio de cartas de crédito instrumentos negociables. El pago puede hacerse de manera directa o indirecta. Un ejemplo de pago indirecto sería la cancelación por el comprador, ya sea en su totalidad o en parte, de una deuda a cargo del vendedor". Complementa el numeral 7 del Anexo III del Acuerdo señalando que "el precio realmente pagado o por pagar comprende todos los pagos realmente efectuados o por efectuarse, como condición de venta de las mercancías importadas, por el comprador al vendedor o por el comprador a un tercero para satisfacer una obligación del vendedor".

Para mayor referencia de los alcances del término "precio realmente pagado o por pagar" recomendamos la lectura del artículo de Juan David Barbosa titulado "El método del valor de transacción", artículo que forma parte de la obra colectiva denominada La Valoración Aduanera en Colombia, Editorial Legis, Primera edición, 2015, pp. 27 - 46. 
otra; acción y efecto de conectar o conectarse"; mientras que "corresponder" significa "tener proporción una cosa con otra; tener relación". ${ }^{16}$

En base a lo señalado, se tiene que las regalías serán susceptibles de adicionarse al valor en aduana sólo en caso que el pago que se efectúe con sujeción a ellas esté directamente relacionado (bajo el esquema de una relación, conexión o correspondencia) con las mercancías importadas que son objeto de valoración. Esto es, que la mercancía importada que contiene el intangible deberá quedar comprendida dentro de los alcances de la licencia o de la relación de mercancías respecto de las que el uso y/o explotación del intangible ha sido autorizado.

Sobre esta base, no resultaría factible realizar un ajuste al valor en aduana de insumos importados sobre la base del pago de regalías efectuado sobre las ventas netas de productos finales elaborados con insumos importados ${ }^{17}$. Ello, debido a que, en dicho caso, el producto comprendido dentro de los alcances de la licencia y cuya venta genera el pago de regalías (producto final elaborado en el país) constituye una mercancía distinta a la que es objeto de importación $y$, por ende, de valoración aduanera (insumos importados). ${ }^{18}$

Al respecto y a mayor abundamiento, resulta sumamente ilustrativa la opinión de Juan Martín Jovanovich en relación con la verificación del requisito objeto de comentario (relación entre el pago de regalías y la mercancía objeto de valoración):

"Si el producto fabricado a partir del insumo (que, en el supuesto, es transformado sustancialmente) es el que se vende bajo la marca o la patente, entonces necesariamente el pago del canon estará relacionado principalmente con la fabricación y venta de dicho producto y no con la compraventa del insumo. ${ }^{119}$

Nótese que el referido autor, también incide en el hecho de la relación directa que tiene que existir entre el pago de la regalía y la mercancía objeto de valoración, descartando la

16 La pertinencia de recurrir al significado de una determinada palabra en el Diccionario de la Real Academia de la Lengua Española ha sido ratificada por el Tribunal Fiscal en múltiples jurisprudencias tales como las Resoluciones 04804-A-2012, 06544-A-2011, 20363-A-2011. En este supuesto se tiene que la elaboración del producto final se efectúa en el país de importación.

18 Situación distinta sería aquella en la que los derechos de licencia de la marca han sido concedidos en relación a la utilización de la misma sobre insumos importados (que tienen por finalidad ser sometidos a un proceso productivo) y que la venta local de dichos insumos (sin transformar) sea la que origine la obligación de pagar regalías al dueño de la marca. En este supuesto el insumo importado deberá haber ingresado al país con la marca impuesta (gravada en él o en el envase que lo contiene).

19 Jovanovich, Juan Martín, "Regalías y derechos de propiedad intelectual. Incidencia y Aplicación en importación". En: II Jornadas Internacionales de Derecho Aduanero, Buenos Aires, 2010, pp. 251. 
procedencia de un ajuste cuando dicho pago está relacionado con la fabricación y venta en el país de importación del producto terminado marcado y no con la compraventa del insumo importado.

Igual razonamiento efectúa Santiago Ibáñez Marsilla ${ }^{20}$ cuando, al analizar el requisito de relación entre el pago de regalías y la mercancía importada bajo los alcances del Acuerdo,

"Por cuanto llevamos dicho, el hecho de que el canon se pague por la venta de unas mercancías que son el resultado de una transformación a partir de las importadas si a algo apunta es, precisamente, a que el canon no guarda relación con las mercancías importadas, y esto será tanto más así cuanto mayor sea el grado de transformación a que se hayan sometido las mercancías".

\section{(ii) Pronunciamiento de la Comunidad Andina.}

Con fecha 30 de abril de 2014 el Tribunal de Justicia de la CAN expidió la Interpretación Prejudicial recaída en el Proceso 03-IP-2014 a fin de absolver el pedido planteado por la Sala de Derecho Constitucional y Social Permanente de la Corte Suprema de Justicia de la República del Perú (Oficio 405-2013-SCS-CS), cuya copia ha sido colgada en la página WEB de la CAN.

Mediante este documento, consta la Interpretación Prejudicial (valga la redundancia) que dicho Tribunal efectuó de los artículos 1, 2, 3, 4, 5 y 17 de la Decisión 571 de la Comisión de la Comunidad Andina, artículos 18 y 26 de la Resolución 846 de la Secretaría General de la Comunidad Andina, Comentario 25.1 numeral 6 de la Resolución 1486 de la Secretaría General de la Comunidad Andina, artículos 7 y 8 del Acuerdo sobre Valoración Aduanera de la OMC, artículo 30 del Reglamento para la Valoración de Mercancías, según el Acuerdo.

En sujeción al análisis efectuado por el Tribunal de Justicia de la CAN, este ente colegiado arribó, entre otras, a las siguientes conclusiones:

\section{Conclusión Cuarta:}

"Cuando los insumos importados incorporan alguna marca relacionada con la licencia, hablaríamos de bienes que contienen derechos de propiedad intelectual y por lo tanto serían susceptibles de ser gravados, esto en concordancia a lo enunciado por el Comentario 25.1, por el contrario, si los insumos no contienen marca, sino que sufren un procedimiento de producción en el país de importación, podemos concluir que no incorporan derechos de propiedad intelectual al momento de la importación, en aplicación de la opinión consultiva 4.9, por lo que el importador no debería soportar ajuste alguno al valor de importación y finalmente para aquellos casos en que 
existan insumos importados con marca que son utilizados en parte para la elaboración del producto terminado al combinar producto importado y producto nacional, el ajuste deberá ser proporcional al valor de dichos insumos importados".

Conclusión Quinta:

"La norma OMC delimita y hace una expresa diferenciación entre producto terminado e insumo para la fabricación, aquí el juez consultante, deberá aplicar para el caso en análisis, si la importación trata expresamente sobre insumo para producir o el producto en sí terminado y en base a ello, verificar el cumplimiento de los tributos que el importador está obligado a cancelar.

Para que aplique el tributo a la mercancía importada, debe necesariamente hablarse de un derecho de propiedad intelectual que permita a la autoridad verificar que el producto importado está relacionado con la marca de la licencia de la cual está haciendo uso el fabricante".

De lo resuelto por el Tribunal de Justicia de la CAN se desprende que no existirá relación entre el pago de la regalía y la mercancía importada objeto de valoración en el caso de importación de insumos sin marca. Ello, sin importar que el insumo importado sea utilizado localmente para la producción del producto terminado al cual se le impone (localmente) la marca cuyo uso genera el pago de regalías.

De otro lado, conforme a lo opinado por el Tribunal de Justicia de la CAN, en el caso de insumos importados con marca, en principio, podría corresponder efectuar un ajuste por pago de regalías. En este supuesto debería verificarse si en la elaboración local del producto final, además de los insumos importados, también participan insumos nacionales, ello, con la finalidad de realizar la respectiva prorrata a los efectos del ajuste del valor en aduana de dichos insumos importados.

(iii) El pago de regalías deberá estar a cargo del comprador y podrá constituir un pago directo o indirecto

El contrato de compraventa constituye un vínculo de derecho establecido entre dos partes plenamente identificadas, vendedor y comprador ( $y$ ninguna otra, salvo disposición expresa del contrato). Si tomamos en consideración que el ajuste sólo se efectúa respecto del precio pactado entre vendedor y comprador podremos inferir que dicho pago (de regalías) debería ser efectuado por el comprador directamente al vendedor 0 , eventualmente, a un tercero pero siempre en beneficio del vendedor (lo cual implicaría que el comprador actúe siguiendo instrucciones del vendedor).

Lo mencionado resulta acorde con lo establecido en el numeral 7 del Anexo III del Acuerdo del Valor de la OMC, el mismo que establece que "el precio realmente pagado o por pagar comprende todos los comprende todos los pagos realmente efectuados o por 
afectarse como condición de la venta de las mercancías importadas, por el comprador al vendedor o por el comprador a un tercero para satisfacer una obligación del vendedor ${ }^{21 "}$.

La lógica detrás de esta disposición se apoya en que si el precio de venta de las mercancías importadas se ha visto disminuido por el hecho de no incorporar en él el pago de regalías, el pago de las mismas debería servir para resarcir al vendedor (quien habría decidido no incorporar dicho concepto en el precio) de manera directa o indirecta, pues se asume que si el vendedor condicionó la venta al pago de regalías quedaría claro que una condición de tal naturaleza sólo podría ser adoptada en la medida que, mediante su cumplimiento, el vendedor se vea necesariamente beneficiado ${ }^{22}$. Así, no cabría concebir

21 En base a una interpretación sistemática de la normativa sobre Valoración Aduanera, en nuestra opinión no existiría impedimento para que la definición de "pago indirecto" prevista para el artículo 1 del Acuerdo (Precio Realmente Pagado o por Pagar - "PRPP") sea utilizada a los efectos de la aplicación del literal c) del numeral 1 del artículo 8 del Acuerdo (ajustes al PRPP por pago de regalías).

Conforme a lo dispuesto en la Norma VIII del Título Preliminar del Código Tributario "al aplicar las normas tributarias podrá usarse todos los métodos de interpretación admitidos por el Derecho". Autores como Nicolás Coviello señalan, en relación con el Método Sistemático, que "Para descubrir el verdadero sentir de la ley, no basta atender al significado de las palabras contenidas en una sola disposición, pues es necesario poner en correlación una disposición con las demás afines que forman toda una institución jurídica, y aun poner ésta en relación con institutos análogos y con los principios fundamentales de todo el derecho. Dada la concatenación de las diferentes disposiciones legislativas, manifiesta u oculta, pero siempre existente, porque responde al enlace de las varias relaciones de la vida social..., es claro que el estudio de las relaciones debe aportar muy copiosa luz para comprender una disposición singular que, aisladamente considerada, puede parecer ininteligible, absurda e irracional, o que tiene un sentido diverso del que debe tener efectivamente. De esta suerte se percibe, también, de qué principio es derivación la norma singular de ley y si constituye una aplicación o una excepción de la misma: y se ve además cuál es su fin práctico, cuáles los posibles efectos en las varias aplicaciones y cuáles los límites de su alcance. Esto se llama elemento sistemático de interpretación". Coviello, Nicolás, Doctrina General del Derecho Civil, Cuarta Edición Italiana, Unión Tipográfica Editorial Hispano-Americana, México, 1938, pp. 78.

Autores nacionales como Fernando Cosio también se pronuncian al respecto señalando que el Método Sistemático - Comparativo: "Analiza el Derecho como un sistema y para analizarlo recurre a la comparación con otras normas, debiendo tomar en cuenta las eventuales diferencias que existan entre las ramas a las que pertenecen las normas utilizadas. Existe interpretación sistemática cuando analizo una norma jurídica en comparación con otras normas que forman parte del mismo dispositivo legal, o bien cuando analizo una norma jurídica en comparación con otras normas de otros dispositivos legales o con el derecho en su conjunto." (el subrayado y negrita es nuestro). COSIO JARA, Fernando. "Manual de Derecho Aduanero", Editorial Rodhas SA.C., Segunda Edición, Lima, 2007, pp. 153.

Precisamente, en base a la lógica que subyace al ajuste aduanero por concepto de regalías, y sobre la base de lo indicado en el Nota 21 precedente, consideramos que, ante la falta de una definición expresa y puntual, resultaría razonable recurrir al concepto de "pago indirecto" relacionado con el "Precio Realmente Pagado o por Pagar", conforme se desprende del numeral 7 del Anexo III del Acuerdo del Valor de la OMC y del ejemplo 
un ajuste por pago de regalías cuando este pago haya beneficiado única y exclusivamente al dueño de la marca o, en todo caso, a cualquier tercero ajeno al vendedor (lo cual podría ocurrir en caso que el dueño de la marca diese instrucciones directas al licenciatario de efectuar el pago de regalías a un tercero pero a su exclusivo beneficio).

Debe tenerse presente que en cualquier caso que el vendedor condicione la venta al hecho que el comprador pague regalías a favor del dueño de la marca o a favor de cualquier tercero quedaría entendido que dicho pago sería efectuado en su beneficio (del vendedor) pues, en caso contrario, el vendedor jamás habría pactado una condición de tal naturaleza (la misma que, incluso, iría (o podría ir) en desmedro o detrimento del precio de venta pactado, pues si la regalía hubiese sido incluida el precio de venta hubiese resultado mayor).

A mayor abundamiento, resulta ilustrativo lo señalado por Julio Carlos Lascano [refiriéndose precisamente al pago indirecto a los fines del ajuste al valor en aduana por concepto de regalías] en el sentido que: "El pago es directo cuando las regalías se pagan al vendedor y es indirecto cuando se pagan a un tercero por indicación de aquél" ${ }^{\prime 23}$.

Dentro de la lógica del ajuste por regalías establecido en el Acuerdo estaremos ante un pago indirecto cuando dicho pago sea efectuado por el comprador siguiendo indicaciones e instrucciones expresas del vendedor. Queda entendido que el vendedor sólo impartirá este tipo de instrucciones si es que del pago de regalías a cargo del comprador pudiese desprenderse algún beneficio para él (el vendedor). No visualizamos un escenario en que el vendedor imparta estas instrucciones si considerase que el pago de regalías pudiera perjudicarlo 0 , en todo caso, le resultase neutro. Las instrucciones a las que hacemos referencia podrían haber sido dispuestas en el contrato de compraventa o, incluso, en algún otro documento expedido por el vendedor y dirigido al comprador con tal finalidad.

\section{(iv) El pago de regalías deberá efectuarse como condición de la venta}

En nuestra opinión cuando el Acuerdo hace referencia a "condición de venta" no hace alusión a una "condición" establecida en el contrato de compra venta entendida como una "modalidad" del acto jurídico, esto es, como "un hecho - futuro e incierto - que arbitrariamente y por la sola voluntad de los declarantes se incorpora al acto jurídico, el que queda supeditado en cuanto a la producción de sus efectos ${ }^{\prime \prime 24}$.

descrito en la Nota al Artículo 1 del Acuerdo [relacionado con la cancelación por el comprador, ya sea en su totalidad o en parte, de una deuda a cargo del vendedor]. Lascano, Julio Carlos, El Valor en Aduana de las Mercancías Importadas, Librería Editorial Osmar D. Buyati, Buenos Aires, 2003, pp. 232. Lima, 1989. 
Consideramos que la condición de la venta a la que alude el Acuerdo está relacionada más con criterios de índole económico y/o de estrategia empresarial en base a los cuales el vendedor toma la determinación de no vender los bienes al comprador si este no acepta efectuar el pago de regalías y en consideración a ello esta regalía (o mejor dicho el valor de la misma) ya no sería costeada en el precio de venta a ser pactado (precio realmente pagado o por pagar en los términos del Acuerdo).

Sobre esta base, la decisión de vender o no vender el producto partiría de consideraciones que el vendedor efectuaría "a priori" a la celebración del contrato. Así, si el comprador no acepta efectuar el pago de regalías conforme a las indicaciones del vendedor sencillamente este último no le venderá nada, con lo que las mercancías nunca serán exportadas al país de importación y menos aún serán objeto de valoración en base a las reglas del Acuerdo.

Sobre esta base se concluye que el condicionamiento de la venta siempre deberá partir del vendedor, pues será este quien, en definitiva: i) deberá asentir con el hecho de transferir la propiedad de bienes que originalmente están bajo su dominio ya sea porque los fabricó o porque los adquirió de terceros [el comprador no podrá adquirir propiedad alguna sobre las mercancías si es que el vendedor no presta su consentimiento para ello]; ii) deberá beneficiarse con el pago de regalías a cargo del comprador; y iii) decidirá finalmente, de corresponder, no incluir el pago de regalías en el precio de final de venta, es decir, no trasladarlo al comprador.

Sobre los alcances del término "condición de venta", resulta ilustrativo lo opinado por Santiago Ibáñez Marsilla cuando, al analizar el requisito de "condición de venta" bajo los alcances del Acuerdo, señala que:

"Si analizamos la doctrina más autorizada concluiremos que no hay discusiones acerca de cuál sea el sentido que deba otorgarse a la expresión "condición de la venta". Coinciden los autores en señalar que la misma hace referencia a una condición impuesta por el vendedor para la venta de las mercancías importadas. Es más, pensaremos que ni si quiera se plantea la posibilidad de entenderlo de otro modo". ${ }^{25}$

Ibañez Marsilla, Santiago, El valor en aduana. Análisis a la luz de su aplicación internacional, Editorial Taric S.A., Primera Edición, 2010, pp. 242.

Es de advertir que cuando Santiago Ibañez se refiere a la "doctrina más autorizada, lo hace en relación con:

Sherman y Glashoff, Customs Valuation, Kluver, 1988, pp. 124

Herrera Idáñez y Goizueta Sánchez, "Valor en Aduana de las mercancías según el Código del GATT". En: ESIC / Revista Aduanas, 1985, pp. 80

Christian Amand, "Calcul de la valeur transactionelle en douane - Journal de Droit Fiscal". 1990, pp. 24 
"Ahora bien, las dificultadas apuntadas respecto de esta interpretación pueden superarse en buena medida si establecemos la matización consistente en que, cuando los cánones se paguen a terceros, su importe sólo se añadirá al precio si el vendedor impuso que se efectuara ese pago. Sistematizando ideas, tendríamos:

- El canon es una condición de la venta siempre y cuando sea un presupuesto de la venta, esto es, siempre y cuando no pueda concebirse la venta de esas mercancías más que bajo el presupuesto del pago de un canon.

- Ello no obstante, cuando el canon en cuestión se pague a un tercero, su importe sólo se añadirá al precio cuando el vendedor haya impuesto tal pago como condición de la venta." ${ }^{\prime 26}$

En el mismo sentido se pronuncia el profesor Julio Carlos Lascano ${ }^{27}$ al señalar que:

"Comencemos por señalar, en primer lugar, que no corresponde el ajuste cuando el Comprador obtiene las mercaderías de un Vendedor que no condiciona la venta al pago de regalías al dueño de la marca. Consideremos el caso de un Importador que paga un canon al dueño de una marca comercial por el derecho a usar esa marca y que contrata separadamente con un Fabricante extranjero la provisión de zapatos con dicha marca mediante un contrato de venta que no prevé ni condiciona la venta al pago de regalías. Ninguna de las partes está vinculada con las demás. Para el Comité Técnico, la obligación de pagar un canon por cada par de zapatos vendidos deriva de un contrato separado que no está relacionado con la venta de las mercaderías para su exportación al país de importación ni constituye una condición de venta, no siendo necesario por este motivo ajustar el precio pagado por las mercaderías. (Se fundamenta en la Opinión Consultiva 4.8)

\section{( ...)}

Para que el pago del canon constituya una condición de venta es necesario que el Vendedor imponga al Comprador la obligación de pagar el canon, sea al propio Vendedor o a un tercero, como requisito ineludible para adquirir las mercaderías. Si el Comprador tiene la opción de adquirir las mercaderías, tanto al titular de la marca como a terceros no vinculados con el dueño de la marca, el pago del canon no es una condición de venta de las mercaderías importadas. (...)" (Precisión y remarcados nuestros). ${ }^{28}$

Ibañez Marsilla, Santiago, El valor en aduana. Análisis a la luz de su aplicación internacional, Editorial Taric S.A., Primera Edición, 2010, pp. 246.

Osmar D. Buyati, Buenos Aires, 2003, pp. 160-161.

Al respecto, resultan interesantes también los precedentes jurisprudenciales citados por Julio Carlos Lascano en la obra referida en la Nota 27 anterior [pp. 159 - 165], en relación con 
En la misma línea se pronuncian Rafael Herrera y Javier Goizueta ${ }^{29}$ en el sentido que: "los cánones o derechos de licencia que deban pagarse a una persona totalmente independiente del vendedor y que estén relacionados con las mercancías, sólo se incluirán al valor, si su pago constituye una condición de venta de las mercancías, impuesta por el vendedor al comprador de dichas mercancías".

De otro lado, téngase presente que el hecho que el licenciante (dueño de la marca) pacte en el contrato de licencia que se reserva el derecho de aprobar los insumos, los proveedores y/o los procesos a fin de resguardar las condiciones técnicas y de calidad de los productos marcados es algo que resulta del todo lógico y que normalmente es pactado por cualquier licenciante en cualquier parte del mundo ya que, más allá del negocio puntual que pueda generarse por el licenciamiento específico de una o varias marcas, está la imagen y reputación comercial del licenciante, la misma que, evidentemente, quedará menguada y se verá afectada (con los enormes perjuicios económicos que ello supone) si los productos objeto de comercialización que se identifican con su marca no se corresponden con los estándares de calidad a los cuales el consumidor ha estado habituado y que son los que precisamente lo inducen a comprar el producto marcado.

Como se aprecia, un condicionamiento de tal naturaleza (esto es, que el producto cumpla con las condiciones y estándares de calidad correspondientes) será necesariamente impuesto por el comprador al vendedor con sujeción al respectivo contrato de licencia que este (el comprador) haya suscrito con el dueño de la respectiva marca

No obstante, en nuestra opinión, la situación descrita anteriormente no constituye, ni podría constituir, el condicionamiento a la venta al que nos hemos referido [que sólo puede impuesto por el vendedor] y que es precisamente al que se hace referencia en el literal c) del numeral 1 del artículo 8 del Acuerdo, a los efectos de proceder a efectuar ajustes al precio realmente pagado o por pagar por concepto de pago de regalías.

fallos en donde había quedado en claro que el vendedor es quien debe imponer la condición de venta a los efectos de proceder al ajuste por regalías [Corte Suprema de Canadá (a menos que el vendedor tenga el derecho de rehusarse a vender las mercaderías bajo licencia a un comprador o repudiar un contrato de venta cuando el comprador no paga las regalías, el pago de éstas últimas no constituye una condición de ventas de las mercaderías; caso Mattel (los cánones y derechos de licencia pagados por el comprador forman parte del valor en aduana únicamente cuando el vendedor tiene autoridad suficiente para rechazar la venta al comprador de las mercaderías licenciadas o repudiar el contrato de venta si el comprador no paga los cánones o derechos de licencia pactados); caso Reebok (las regalías pagadas por el comprador al vendedor de las mercaderías por aplicación de un contrato de licencia firmado entre las mismas partes, separadamente y sin conexión con el contrato de venta, no se deben adicionar al valor en aduana de las mercaderías importadas)]. según el Código del GATT". En: Revista Aduanas, Ediciones ESIC, Madrid, 1985. 
El condicionamiento de venta no podría partir del comprador puesto que, en dicho supuesto, estaríamos ante una "condición de compra", situación que, al originarse en un interés y lógica comercial opuestos o diferentes a los del vendedor, haría surgir, por lo menos, serios cuestionamientos en torno a la concurrencia de los demás requisitos de procedencia del ajuste a los que hace referencia el literal c) del numeral 1) del artículo 8 del Acuerdo. Más aún, en este supuesto, el vendedor quedaría al margen del móvil (motivación) del comprador (licenciatario) para imponer la "condición de compra"; móvil que, dicho sea de paso, derivará de un contrato distinto (Contrato de Licencia) en el que el vendedor no participa ni tiene ningún tipo de injerencia. ${ }^{30}$

Además, deberá tenerse presente que, ante un pedido de fabricación de productos en el que se deba utilizar intangibles protegidos por las leyes de propiedad intelectual (sea que este pedido se efectúe como consecuencia o no de un sublicenciamiento previo), lo que sí resultaría razonable es que el fabricante (vendedor) pueda exigir y terminar por imponer contractualmente como condición para fabricar y/o para vender el producto que quien encarga el pedido (licenciante - comprador) cuente efectivamente con los derechos de licencia que se irroga, pues de lo contrario dicha fabricación y posterior venta constituirían actos que infringirían los derechos de propiedad intelectual del dueño del intangible lo cual podría desencadenar, incluso, en denuncias penales contra quienes infrinjan tales derechos.

En efecto, un fabricante diligente deberá exigir a quien le encarga la fabricación de productos marcados que le acredite no sólo que cuenta con un contrato de licencia sino, además, que dicha licencia se mantiene vigente a la fecha que el encargo es efectuado, circunstancia que debería pasar por la verificación de la inscripción (y vigencia de inscripción) de tal contrato en el registro especial a cargo de la agencia de propiedad intelectual del país del licenciante (comprador).

Como es de ver, lo que verdaderamente interesará al vendedor es que la licencia otorgada al comprador (licenciatario) se mantenga vigente y no tanto que el comprador

$30 \quad$ Si fuese el caso que el comprador sea quien imponga la condición para la compra (y no una de venta) para proceder a suscribir el respectivo contrato de compraventa no se explicaría de qué modo el pago que este efectuaría por concepto de licencia al dueño del intangible pueda beneficiar directa o indirectamente al vendedor, quien, al no haber participado en la decisión de imponer este condicionamiento debería permanecer al margen de las consecuencias (económicas o no económicas) de tal decisión, circunstancia que, además, dejaría serias dudas en cuanto a si resultaba razonable que dichas regalías debieran haber formado parte del precio de venta (supuesto que hubiese podido servir de sustento para el ajuste tal como lo veremos más adelante). De otro lado, tampoco resultaría lógico que el propio comprador se autoimponga una obligación en una relación contractual (compraventa) que, en principio, resultaría ajena y distinta a la relación contractual que mantiene dicho comprador (licenciante) con el dueño del intangible (licenciatario). 
pague o no pague la licencia respectiva. En otras palabras, mientras la licencia otorgada al comprador mantenga vigencia y validez, el vendedor seguirá fabricando y vendiendo los productos sin cuestionamiento alguno y sin importarle si dicha licencia es onerosa 0 gratuita, si el pago de la regalía a cargo del comprador se llega o no a efectuar, o si, por último, el licenciante, ante el incumplimiento de pago del licenciatario -comprador, decide otorgar periodos de gracia para el pago, fraccionar la deuda o, incluso, condonar la misma. En función a lo señalado, consideramos que el "condicionamiento" a la venta [relacionado con la "licencia vigente"] que, en el supuesto comentado, de modo natural y razonable podría imponer el fabricante - vendedor al comprador - licenciante, resultaría diferente a aquél al que hace referencia el Acuerdo del Valor de la OMC [relacionado con el "pago de la regalía"].

Como se aprecia, el pago de la regalía no necesariamente deberá constituir una "condición de venta" impuesta por el vendedor. Consideramos que no podría inferirse algo así o considerarse que "per se" y en todos los casos debería ocurrir ello (salvo, por supuesto, que el vendedor haya establecido esto de modo expreso). Por el contrario, creemos que si algo hubiese que inferir es que la condición de venta quedaría determinada por el hecho de mantener vigente la licencia, vigencia que podría o no mantenerse en forma independiente a que la regalía sea pagada o no. La vigencia de la licencia no equivale a pago de regalías ni necesariamente es consecuencia de este último.

En efecto, normalmente los contratos de licencia de uso de marcas supeditan su vigencia a diferentes factores. Uno de ellos, por supuesto, es el pago oportuno de la regalía. Empero, en estos contratos, constituye pacto habitual el que el licenciante (dueño de la marca) se reserve el derecho de dejar sin efecto de contrato ante la falta de pago de la regalía. Es decir, la práctica regular es que la falta de pago de la regalía no active en automático la resolución del contrato de licencia sino sólo que haga nacer el derecho del licenciante a resolver dicho contrato. Esto es, el licenciante decidirá si el contrato de licencia continúa o no, resultando un supuesto del todo válido $y$, por cierto comercialmente viable, que a pesar de la falta de pago de la regalía el licenciante decida continuar con el respectivo contrato. En este escenario, el contrato de licencia no quedaría resuelto con lo que no existiría una razón valedera para asumir que el vendedor dejará de abastecer al comprador (licenciatario) de los productos marcados.

Reiteramos que no existe una razón válida para suponer "a priori" que ante la falta de pago de la regalía el contrato de licencia debería necesariamente quedar resuelto. Así, cabe la posibilidad contractual que el licenciante decida continuar con el contrato de licencia a pesar de la falta de pago de las regalías y decidir, de mutuo acuerdo con el licenciatario, qué es lo que harán con el saldo impago. Esto es: i) podrían financiar dicho saldo (cuotas periódicas sujetas a un interés); ii) podrían cuantificarlo y pactar un modo distinto de pago que no represente necesariamente la entrega de un monto de dinero 
(entrega de acciones del licenciatario, por ejemplo); ó iii) hasta podrían condonarlo, así de sencillo.

En el escenario analizado el continuar o no con el contrato de licencia es una facultad del licenciante, quien deberá evaluar qué es lo que más le conviene ante la cesación de pago de las regalías; cesación que no tiene porque ser necesariamente definitiva, pues podría ocurrir que, por ejemplo, el licenciatario incurra en una momentánea iliquidez de la cual pueda salir airoso con el transcurso del tiempo y que el licenciante esté dispuesto a esperar dicho tiempo.

Como se aprecia, el vendedor no juega ningún rol en la relación entre el licenciante y licenciatario. El vendedor resulta del todo ajeno a esta relación contractual. El vendedor no puede controlar las motivaciones que puedan llevar al licenciante a continuar o no continuar con el contrato de licencia a pesar de la falta de pago de la regalía a cargo del licenciatario (comprador). $Y$ es que realmente al vendedor no le importarán dichas motivaciones puesto que el único parámetro objetivo y razonable que realmente lo condicionaría a continuar con el suministro de las mercancías marcadas es que la licencia se mantenga en vigencia, circunstancia que, como hemos mencionado, no depende directamente del pago de regalías.

A mayor abundamiento, es de es precisar que el pago de regalías no es la única causal que podría ocasionar la resolución del contrato de licencia. Siendo que la reputación y prestigio comercial de la marca del licenciante están en juego, resulta lógico que para el licenciante resulte especialmente importante, por ejemplo, el hecho de conocer quiénes son los accionistas de la empresa licenciataria. Es decir, normalmente para licenciante será muy importante saber quiénes son las personas detrás de la empresa que utilizará su marca. Por ello, es que en los contratos de licencia se suelen pactar cláusulas en función a las cuales el cambio de accionariado del licenciatario deberá ser puesto en conocimiento del licenciante dentro de un plazo determinado reservándose el licenciante el derecho de continuar o no con el contrato de licencia. En este escenario, podría ocurrir que el licenciatario se encuentre escrupulosa y diligentemente al día en los pagos de la regalía a su cargo pero que, no obstante, la relación de nuevos accionistas no sea del agrado del licenciante y que, por dicha razón, este decida poner fin al contrato de licencia. ¿Podríamos decir acaso, en este supuesto, que la falta de pago de regalías habría resultado o debería resultar un condicionante para la venta de las mercancías importadas? Por supuesto que no.

Como vemos, de los ejemplos expuestos se puede apreciar que para el vendedor lo realmente importante será que el contrato de licencia siga en vigencia y no que la regalía sea pagada por el licenciatario al licenciante. Situación que evidencia, a su vez, que lo natural y lógico será que el vendedor condicione la venta de las mercancías importadas a la acreditación de una licencia vigente, siendo este tipo de condicionamiento lo que, en 
nuestra opinión, podría inferirse de la relación contractual entre el vendedor y el comprador. Por ello, el hecho de condicionar la venta al pago de las regalías no debería ser algo que pueda o deba intuirse o suponerse sino que debería estar debidamente acreditado y surgir de modo claro de la documentación que sustenta la relación contractual entre vendedor y comprador.

(v) Los cánones y derechos de licencia no deberán estar incluidos en el precio realmente pagado o por pagar

Constituye requisito para poder ajustar el valor en aduana declarado por el importador que las regalías pagadas no estén ya incorporadas en el precio de venta de las mercancías importadas objeto de valoración. Esto, por la sencilla razón que en caso que las regalías ya hayan sido incorporadas en el precio de venta, el valor de las mismas ya habría sido transferido al comprador vía dicho precio y habría sido también tomado en consideración a los efectos de la determinación del precio realmente pagado o por pagar por estas mercancías al momento de la valoración en aduana. Es decir, el valor de las regalías habría sido ya incluido en el precio facturado $y$, por ende, declarado en el despacho de importación (no habría nada más que declarar y/o ajustar con posterioridad).

Esto supondría, en principio, que sea el vendedor quien cuente con una licencia otorgada por el titular del intangible y que el valor de la regalía a su cargo haya sido considerado en la estructura de costos del producto objeto de venta, y, como ya se mencionó, se haya trasladado dicho costo al comprador vía precio.

Teniendo esto en consideración, la lógica del ajuste por pago de regalías estribaría en el hecho que, debiendo haber sido costeado este valor en el precio de venta, dicho valor por alguna razón no fue incorporado en él con lo que el precio de venta carecería de uno de los elementos de su estructura (partiendo de la estructura teórica que debió haber tenido) $y$, por ende, se presentaría como un menor valor a efectos aduaneros.

Siguiendo este razonamiento, se tendría que en caso que el valor de la regalía no constituya parte de la estructura del precio de venta (por ejemplo, en caso que el vendedor no cuente con obligación de pagar regalía alguna al dueño del intangible), no existirá ninguna razón que justifique su incorporación a dicho precio $y$, por tanto, se carecería del requisito indispensable para proceder al posterior ajuste, esto es, que dicho valor de regalía haya debido formar parte de la estructura de costos en función a la cual el vendedor determinó el precio de venta finalmente pactado con el comprador.

Ello no obstaría para que el vendedor (bajo sus propias motivaciones) pueda apartarse de la lógica estructural de la situación descrita y decida condicionar la venta de las mercancías importadas al hecho que el comprador efectúe el respectivo pago de regalías sobre la base, por ejemplo, de la venta local de los productos marcados en el país de 
importación. Claro está que este tipo de condicionamiento deberá partir, como ya hemos mencionado, del propio vendedor y constar en documentos generados por él mismo instruyendo al comprador a actuar de dicha manera.

\section{Efectos de la vinculación}

Conforme al numeral 4) del artículo 15 del Acuerdo existe vinculación entre las partes intervinientes en el contrato de compraventa internacional en los siguientes casos:

a) Si una de ellas ocupa cargos de responsabilidad o dirección en una empresa de la otra;

b) Si están legalmente reconocidas como asociadas en negocios;

c) Si están en relación de empleador y empleado;

d) Si una persona tiene, directa o indirectamente, la propiedad, el control o la posesión del 5 por ciento o más de las acciones o títulos en circulación y con derecho a voto de ambas;

e) Si una de ellas controla directa o indirectamente a la otra;

f) Si ambas personas están controladas directa o indirectamente por una tercera;

g) Si juntas controlan directa o indirectamente a una tercera persona, o

h) Si son de la misma familia.

De presentarse alguno de estos supuestos, y conforme dispone el literal a) del numeral 2 del artículo 1 del Acuerdo, no resultaría procedente la aplicación del Método del Valor de Transacción de las Mercancías Importadas (Primer Método Valoración en Aduana), salvo que se demuestre que dicha vinculación no afectó el precio de venta.

Ninguna otra disposición del Acuerdo otorga algún otro efecto jurídico a la "vinculación". Sobre esta base, la vinculación no ha sido establecida por el Acuerdo como un requisito para efectuar un ajuste al precio realmente pagado o por pagar por las mercancías importadas.

Puntualmente en el caso de los ajustes por concepto de pago de regalías es de mencionar que el literal c) del numeral 1) del artículo 8 del Acuerdo en ningún momento señala que la vinculación entre vendedor y comprador y/o entre ellos y el dueño del intangible constituya un requisito de procedencia del ajuste por pago de regalías ni tampoco que pueda producir algún efecto especial en lo que a este tipo de ajuste se refiere.

No obstante lo señalado, se advierte que el Comité Técnico de Valoración en Aduana ha expedido opiniones consultivas en las que se vislumbraría con meridiana claridad la 
orientación de este ente de atribuir determinados efectos a la "vinculación" entre las partes contratantes. Aunque estos efectos resultarían determinantes a fin de verificar si se cumple o no con el requisito de "condición de la venta" al que nos hemos referido anteriormente, se advierte también que dichos "efectos" no contarían con una base legal establecida en el Acuerdo sino que corresponderían a consideraciones subjetivas de este Comité.

En efecto, si analizamos la Opinión Consultiva 4.8. y la Opinión Consultiva 4.11 expedidas por el Comité llegaremos a la conclusión que éstas, en esencia, están referidas al mismo esquema: de un lado, el vendedor (fabricante) vende mercancías al comprador (importar - licenciatario) sobre la base de un contrato de compraventa internacional suscrito entre ambos y, de otro, el comprador suscribe un contrato de licencia de marca con el dueño de la misma (licenciante). La gran diferencia entre los casos descritos en cada Opinión Consultiva estriba en que mientras que en el primer caso no existe vinculación entre ninguna de las partes intervinientes (vendedor, comprador y dueño de la marca), en el segundo caso esta vinculación si existe (tanto el vendedor como el comprador están vinculados a la casa matriz que a su vez es la dueña de la marca). Es decir, ambos casos son prácticamente idénticos, la única diferencia es la vinculación entre las partes.

En la Opinión Consultiva 4.8. (no hay vinculación) el Comité Técnico concluyó que no existía "condición de la venta" y que por ello el pago de regalías no resultaba ajustable a efectos aduaneros. En la Opinión Consultiva 4.11 (si hay vinculación) el Comité concluyó lo contrario, esto es, que si existía "condición de la venta" y que, por ello, el pago de regalías resultaba ajustable.

Conforme hemos adelantado, en nuestra opinión lo establecido por el Comité Técnico mediante la Opinión Consultiva 4.11 responde a un criterio subjetivo que no encontraría base legal [o por lo menos una base legal clara] en el Acuerdo, teniendo en consideración que para el Acuerdo la "vinculación" no es un concepto que se encuentre relacionado con los ajustes al precio realmente pagado o por pagar por la mercancía importada.

Entenderíamos que para el Comité, el hecho que una operación de estas características todas las partes se encuentren vinculadas implicaría que éstas actuarían siguiendo directrices y/o políticas comunes, lo cual obligaría a efectuar un análisis de la operación en su conjunto con lo que las estipulaciones del contrato de compraventa suscrito entre el vendedor y el comprador no podrían ser analizadas de modo aislado de las disposiciones del contrato de licencia suscrito entre el dueño de la marca y el licenciatario (comprador). En función a ello, se asume que el Comité habría considerado que existiría una suerte de condición de venta "implícita" en una operación "tripartita" respecto de la cual ninguna de las partes intervinientes podría resultar ajena ni quedar desligada. 
Más allá que la conclusión del Comité pueda resultar o no razonable, insistimos en nuestra posición que dicha interpretación no encontraría sustento en las disposiciones del Acuerdo, motivo por lo cual resulta cuestionable.

Dicho cuestionamiento se extiende a la posibilidad real de aplicar de la Opinión Consultiva 4.11 sobre la base de los efectos que el Acuerdo establece ante la existencia de vinculación entre vendedor y comprador.

Al respecto, debemos señalar que la eventual posibilidad de aplicar la Opinión Consultiva 4.11 reposa en el hecho que la vinculación entre vendedor y comprador no haya afectado el precio realmente pagado o por pagar por las mercancías importadas, pues de lo contrario el Método del Valor de Transacción sería rechazado y, consecuentemente, ningún ajuste podría ser realizado (ya que éstos sólo resultarán aplicables si es que este Método, a su vez, resulta aplicable).

De otro lado, si la vinculación no afectó el precio realmente pagado o por pagar y, consecuentemente, cabría potencialmente aplicar los ajustes dispuestos por el Acuerdo (en la medida que se cumplan con los requisitos establecidos para tal fin), nos encontraríamos ante partes vinculadas que se comportarían como si no lo estuviesen. En tal supuesto, nos preguntamos ¿cuál es la base legal, con sustento en el Acuerdo, que establece que a las partes vinculadas que se comportan como no vinculadas se les debe tratar de diferente forma que a las partes no vinculadas?. Pensamos que dicha base legal no existe.

Entonces ¿por qué expedir dos Opiniones Consultivas que arriban a conclusiones distintas en base a si hay o no vinculación entre las partes cuando el propio Acuerdo no establece, ni da pie para interpretar, que dicho trato diferenciado deba ser efectuado?

En nuestra opinión las partes vinculadas que se comportan como no vinculadas deberían recibir el mismo trato que las partes no vinculadas, con lo que jurídicamente sólo resultaría justificable la existencia de la Opinión Consultiva 4.8

Lo expuesto resulta del todo coherente pues conforme al Acuerdo la vinculación entre las partes no debe producir efectos "per se", sino que dichos efectos (que sólo consisten en aceptar o no el Método del Valor de Transacción) quedan condicionados al hecho que las partes vinculadas hayan estructurado la operación en función a la vinculación existente entre ellas y que, sobre dicha base, el precio de venta se haya visto afectado. En caso contrario, esto es cuando las partes vinculadas hayan actuado como partes no vinculadas, dicha "vinculación" (concebida en un plano estrictamente formal) no produciría ningún efecto en materia de valoración aduanera.

VI. Regulación a nivel de la comunidad andina (CAN) y comentario 25.1 del comité técnico del valor en aduana 
La normativa comunitaria andina también regula el tema de la valoración aduanera de las mercancías importadas, razón por la cual es importante conocer qué es lo que ésta dispone en relación con el tema que nos convoca en el presente artículo.

A modo de antecedente, es de indicar que el numeral 2 del artículo 26 de la Resolución 846 de la Comunidad Andina - CAN (Reglamento Comunitario de la Decisión 571 - Valor en Aduana de las Mercancías Importadas) disponía que:

"Cuando el comprador pague un canon o un derecho de licencia a un tercero,
la condición de que esté relacionado con la mercancía que se valora y que
constituya una condición de venta de dicha mercancía, sólo se considerará
cumplida, si el vendedor o una persona vinculada al mismo, exige al
comprador que efectúe dicho pago. [Primer Párrafo]

A tales efectos, se considerará que la condición de venta no necesariamente debe estar prevista de manera expresa en un contrato sino que ésta puede probarse con los elementos de hecho de las operaciones comerciales" [Segundo Párrafo].

Como se aprecia, la expresión "a tales efectos" conectaba el Segundo Párrafo con el Primer Párrafo, por lo que, necesariamente, dicho Segundo Párrafo debía ser entendido como una precisión de los alcances del primero; esto es, dentro de la consideración que la condición de venta es impuesta al comprador sólo (es decir, únicamente) por el vendedor (o, en todo caso, por una persona vinculada a él). Así, "los elementos de hecho de las operaciones comerciales" a los que se hace referencia en el Segundo Párrafo en cuestión, únicamente podrían estar referidos a la relación comercial entre vendedor y comprador.

El artículo en referencia fue modificado por el numeral 2 del artículo 28 de la Resolución 1684 de la CAN $^{31}$ (actualización del reglamento comunitario de la Decisión 571 - Valor en Aduana de las Mercancías Importadas), siendo el texto actual como sigue:

"para evaluar los incisos a) y b) precedentes ${ }^{32}$, se deberá tomar en cuenta lo señalado en el Comentario 25.1 del Comité Técnico de Valoración en Aduana.

31 Esta Resolución fue publicada en la Gaceta Oficial de la Comunidad Andina (CAN) el 28 de mayo de 2014 y entró en vigencia el 28 de julio de 2014.

32 El inciso a) señalaba que para que se ajuste el precio realmente pagado o por pagar por las mercancías importadas, el pago de la regalía debería estar relacionado con la mercancía que se valora.

El inciso b), por su lado, señalaba que para que se ajuste el precio realmente pagado o por pagar por la mercancía importada, el pago de las regalías debería constituir una condición de venta de dicha mercancía. 
A tales efectos, se considerará que la condición de venta no necesariamente debe estar prevista de manera expresa en un contrato sino que esta pueda probarse con los elementos de hecho de las operaciones comerciales" (Subrayado nuestro).

Como se aprecia, se ha producido un cambio sustancial respecto del primer párrafo de la norma antes citada. En efecto, ya no se hace referencia expresa a que la "condición de venta" [respecto del pago de regalías] impuesta al comprador debe partir del vendedor o, en todo caso, de una persona vinculada a este. Ahora dicha precisión ha sido sustituida por una referencia al Comentario 25.1 del Comité Técnico de Valoración en Aduana, por lo cual resulta importante analizar su contenido.

El Comentario 25.1 constituye un comentario general expedido por el Comité Técnico en relación con los "cánones y derechos de licencia abonados a terceros" y de él se desprende que, a los efectos del análisis de la procedencia de un ajuste por concepto de pago de regalías resultará importante revisar no sólo el contrato de compraventa internacional suscrito entre el vendedor y el comprador sino también el contrato de licencia de uso de marca suscrito entre el licenciante (dueño de la marca) y el licenciatario (comprador).

Debemos indicar también, para no perder la perspectiva de lo que en este Comentario se indica, que este constituye, como su propio texto señala, "una guía para la interpretación y aplicación del artículo 8.1. c) del Acuerdo en casos en que un canon o un derecho de licencia se paga a un tercero que no está vinculado al vendedor".

La naturaleza de "guía" (recomendación o sugerencia) de este comentario no debe ser soslayada. Así, el hecho de haber quedado incorporado dicho comentario a la legislación andina y, por ende, a la legislación nacional de los países miembros (se incluye al Perú), no supone que este pueda ser aplicado por la autoridad aduanera de manera "automática" sin siquiera analizar las características particulares del caso concreto de que se trate. Ello queda corroborado cuando en la parte final del referido Comentario se señala que "cada caso deberá examinarse individualmente teniendo en cuenta las circunstancias que le sean propias", disposición que se encuentra del todo alineada con lo señalado, a su turno, por el profesor Daniel Zolezzi en el sentido que "no es aconsejable aplicar criterios generales que posterguen las particularidades del caso $^{\prime \prime 3}$, haciendo referencia a que resulta indispensable analizar caso por caso, para determinar si existe $o$ no condición de venta a los fines de la valoración aduanera.

33 Zolezzi, Daniel, Valor en Aduana (Código Universal de la OMC), Segunda Edición, Editorial La Ley S.A.E, Buenos Aires, 2008, pp. 166. 
En relación a la modificación dispuesta por la Resolución 1684 de la CAN a la cual hemos hecho referencia, es de indicar que, en nuestra opinión, la remisión directa al Comentario 25.1 origina un alcance distinto y más amplio que aquel que se desprendía del texto original del artículo 26 de la Resolución 846. Ello, debido a que, conforme a este Comentario, y como ya habíamos adelantado, a los efectos del análisis de la "condición de la venta" se deberá analizar (a fin de tener "mayores indicios") no solo el contrato de compraventa internacional u otra documentación que fluya de la relación entre el vendedor y el comprador, sino también el contrato de licencia suscrito entre el dueño del intangible licenciado y el licenciatario - comprador de las mercancías importadas.

Lo antes señalado fluye del texto del Comentario 25.1 cuando en él se indica que "un factor clave que permite determinar si el comprador debe pagar el canon o derecho de licencia como condición de venta de las mercancías importadas reside en saber si el comprador no podría comprar las mercancías importadas sin pagar dicho canon o derecho de licencia. Cuando el canon se paga a un tercero vinculado al vendedor de las mercancías importadas, es más probable que el pago del canon o derecho de licencia constituya condición de venta que cuando dicho canon o derecho de licencia se paga a un tercero no vinculado con el vendedor".

Apréciese que del texto citado, se desprende nuevamente la vocación de "guía" (y no de imposición) del Comentario 25.1 al emplearse la frase "es más probable" al referirse al supuesto en el que el pago de la regalía se efectúa a un tercero vinculado al vendedor. En sujeción a ello, ni siquiera en este último supuesto (vinculación entre el vendedor y el tercero que recibe el pago de la regalía) debería inferirse a priori que la regalía pagada deberá ser "ajustable" sin antes revisar en detalle las particularidades del caso.

De otro lado, resulta bastante cuestionable que en el Comentario 25.1 se señale que podría existir una "condición de venta" a los efectos del Artículo 8.1. c) del Acuerdo del valor de la OMC en caso de que el comprador no pueda comprar las mercancías importadas sin pagar la regalía. Ello, desde nuestro punto de vista, constituye una "condición de compra" pero no una "condición de venta"; condición, esta última, que debería ser establecida en atención a consideraciones que atañen al vendedor, en atención a las cuales tal condicionamiento debería verse materializado en el respectivo contrato de compraventa y, por ende, surtir efectos en la relación vendedor-comprador, tal como ha sido desarrollado en extenso en el presente artículo y lo que resulta, además, coincidente con lo señalado por la doctrina a la que hemos hecho referencia.

Bajo esta consideración la existencia del contrato de licencia y las estipulaciones que puedan haber pactado en él, el licenciante y el licenciatario (comprador); resultarán ajenas a la fabricación y/o venta a cargo del vendedor. Nos reiteramos en el hecho que para un vendedor diligente, a los efectos de la fabricación y/o venta de los productos marcados, bastará comprobar que el comprador cuenta con licencia vigente respecto del 
intangible relacionado con la fabricación y/o incorporado en los productos objeto de venta.

Por ello, sostenemos que analizar la "condición de venta" desde la perspectiva del comprador ( $y$ de las relaciones comerciales que este mantenga con terceros en las que el vendedor no interviene) resulta un error.

Sin perjuicio de ello, y atendiendo a la literalidad del artículo 28 de la Resolución 1684, consideramos que, en todo caso, la remisión al Comentario 25.1 debería ser tomada con responsabilidad y criterio adecuado a los efectos de extraer conclusiones fundadas en derecho en cada caso particular que sea analizado (sin pretender extraer conclusiones generales). Ello, al margen de que nos encontremos en operaciones en las que exista o no vinculación entre el vendedor y el licenciatario.

\section{Reflexiones sobre la procedencia de aplicar una multa en estos casos}

Lo que normalmente acontece en la práctica es que el importador considera, de buena fe, que no se encontraba obligado a incorporar el monto de dinero pagado por concepto de regalías al valor en aduana de las mercancías importadas debido a que no advierte relación alguna entre dicho pago y aquello que compra a un tercero sobre la base de una relación contractual distinta.

El artículo 192, inciso c), numeral 1 de la Ley General de Aduanas, establece que cometen infracción sancionable con multa los declarantes que "formulen declaración incorrecta o proporcionen información incompleta de las mercancías respecto a su valor".

La declaración que menciona la ley se refiere a datos objetivos que permiten al fisco aforar la mercancía adecuadamente. Así, por ejemplo, la cantidad, calidad y el peso de la mercancía y el precio al que es adquirida.

En cambio, no cabe exigir al administrado que aporte conclusiones jurídicas, como lo sería el declarar que el pago de regalías integra el valor en aduana de las mercancías importadas (máxime si ninguna estipulación del contrato de compraventa internacional así se lo indica).

"Las discrepancias de valoración, que son distintos modos de interpretar una ley, no constituyen falsedad ni inexactitud en la declaración". Así lo afirma el profesor Daniel Zolezzi en dos artículos suyos sobre la materia; el primero denominado "¿Una infracción de tipo muy abierto?", publicado en el No 19 de la Revista de Estudios Aduaneros, Buenos Aires, Segundo Semestre 2007 - Primer Semestre 2008 (p. 133) y el segundo publicado en la Guía Práctica de Comercio Exterior 148, Buenos Aires, agosto de 2009. 
Como es de ver, el importador puede discrepar con el fisco en cuanto a si una regalía constituye o no concepto ajustable y declarar, conforme a su parecer, sobre un pasaje opinable de la Ley. Al hacerlo, está dejando de manifiesto su punto de vista y no una información inexacta, que es lo que tipifica como infracción la Ley General de Aduanas.

Esta ley castiga a quienes "formulen declaración incorrecta o proporcionen información incompleta de las mercancías". Ninguna de estas dos cosas ocurre de producirse una discrepancia entre el importador y la Aduana en cuanto al derecho aplicable. Ese no es ese el reproche que estatuye el artículo 192 de la Ley General de Aduanas. Diferencias de opinión en materia legal no constituyen ni una "declaración incorrecta" ni una "información incompleta". Una interpretación "elástica" de esa figura le conferiría tal amplitud, que la haría incompatible con el derecho punitivo actual y, más aún, con el Estado de Derecho.

\section{En síntesis}

- La valoración aduanera constituye un tópico que reviste especial complejidad que tiene que ver con la determinación de la base imponible de los tributos de importación (aspecto cuantitativo de la hipótesis de incidencia tributario-aduanera).

- $\quad$ El Acuerdo del Valor en Aduana de la OMC constituye la norma que, a nivel internacional, se ocupa de la valoración aduanera de las mercancías importadas. El Comité Técnico de Valoración en Aduana emite instrumentos tendientes a generar uniformidad en cuanto a la aplicación de las disposiciones del Acuerdo. En el Perú, el hecho que los instrumentos del Comité (que han sido concebidos como criterios orientadores y no vinculantes) hayan sido incorporados a la legislación nacional podría originar problemas en cuanto a la aplicación de esta normativa.

- $\quad$ Las reglas sobre valoración aduanera se aplican para determinar el valor en aduana de las mercancías importadas, concebidas éstas como bienes físicos.

- El Método del Valor de Transacción de las Mercancías Importadas constituye el primer y principal método de valoración. Este método se sustenta en el precio realmente pagado o por pagar por las mercancías importadas, el mismo que puede ser susceptible de ajustes (incrementos).

- Los requisitos para la aplicación del ajuste al precio realmente pagado o por pagar por concepto de pago de regalías (como para cualquier otro ajuste) son concurrentes entre sí debiendo estar necesariamente presentes todos y cada uno de dichos requisitos en la operación analizada para que el ajuste resulte procedente. Cada uno de los requisitos para la procedencia del ajuste deberá ser analizado en detalle pues la casuística en este tipo de operaciones resulta bastante rica y los presupuestos de análisis no siempre pueden resultar siendo los mismos. 
- La vinculación, conforme al Acuerdo, únicamente produce efectos en lo relativo a la determinación de si el Método del Valor de Transacción de las mercancías importadas podría o no ser tomado en consideración para establecer el valor en aduana aplicable. La vinculación no constituye un requisito para la aplicación de los ajustes establecidos en el propio Acuerdo, razón por la cual el concepto de "vinculación" resultaría legalmente ajeno al concepto de "ajuste" al precio realmente pagado o por pagar. Por esta razón, la Opinión Consultiva 4.11 expedida por el Comité Técnico resultaría cuestionable.

- En base a una reciente modificación de la normativa andina en materia de valoración aduanera, resultaría de importancia, a efectos de determinar la procedencia de un ajuste por pago de regalías, analizar no sólo el contrato de compraventa internacional suscrito entre el vendedor y el comprador de las mercancías importadas, sino también el contrato de licencia de uso de marca suscrito entre dicho comprador y el titular de la marca (licenciatario). Ello, tomando como referencia lo señalado por el Comité Técnico en el Comentario 25.1.

- La discrepancia de interpretación jurídica entre el importador y la autoridad aduanera en temas complejos como, por ejemplo, si procede o no un ajuste por concepto de pago de regalías, no puede asemejarse a una declaración incorrecta o incompleta sobre el valor de las mercancías importadas. Por esta razón, la aplicación de multas en estos casos resulta cuestionable. 